\title{
Sócrates, consumismo capitalista $y$ buen vivir
}

Alejandro Otero Ordoñez*

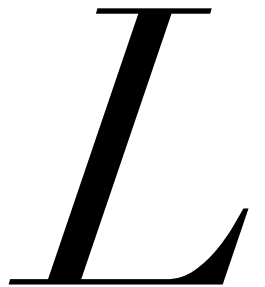

A FORMA en que Sócrates se relacionaba con la gente que lo rodeaba parecía ser para él tanto un don como una maldición. El nivel de conciencia que llegó a desarrollar sobre su propia ignorancia ("sólo sé que no sé nada"), y el amplio espacio vacío para aprender de la información y la experiencia, le daban un agudo sentido del deber para la autorreflexión y el fortalecimiento del carácter interno. Su amor a esta vocación y ayudar a sus conciudadanos eran mucho más valiosas que cualquier ganancia $(o$ pérdida) personal, física o social que pudiese haber tenido a su disposición. Si la felicidad o la conciencia de una buena vida (o como le llaman los indígenas de Los Andes del siglo xxI, el "buen vivir" o sumak kawsay), de acuerdo con Sócrates y sus seguidores, no se puede lograr con adquisiciones externas, ¿por qué los medios y los grupos dominantes en nuestra sociedad insisten en un consumo capitalista glotón?

Propongo responder a esta pregunta a partir de un análisis de la Apología de Sócrates de Platón y estudios relacionados con ella. Mi argumento es que nuestro descuido del "alma" o la vida espiritual interna y cierto entendido común de que somos sabelotodo, nos causan una compulsión para la satisfacción y el reco-

* Terapeuta Clínico de Adicciones; Licenciado en Estudios Ambientales Humanos por Simon Fraser University, Canadá. nocimiento (material) externos. Aunque hoy en día no se les dé mucha importancia a las teorías socráticas, todavía nos pueden ayudar para lograr un sentido de satisfacción y felicidad disfrutando lo que es realmente la buena vida.

Mediante la continua contemplación y autoevaluación, Sócrates llegó a entender que la sabiduría que buscaba era mucho más poderosa y digna de honrar que cualquier ganancia o pérdida personal, que cualquier alabo o persecución. Él sentía tener una vocación más alta a la cual tenía que ceñirse por sobre todas las cosas. Así lo explica Platón en su Apología: "Hombres de Atenas, los honro y los amo; pero yo obedeceré a Dios antes que a ustedes, y mientras tenga vida y fuerzas nunca dejaré la práctica y la enseñanza de la filosofía [...]". Aparte de su afirmación deísta, podemos entender este planteamiento socrático como su decisión de abocarse a la vida interna de la reflexión que tiene su recompensa propia, también interna. En esta sección, Sócrates plantea una pregunta que sigue teniendo relevancia para los ciudadanos del mundo globalizado del siglo XXI. Platón continúa: “`No les da vergüenza acumular la mayor cantidad de dinero $y$ honra y reputación, e interesarse tan poco por la sabiduría y la verdad y el mayor mejoramiento del alma, a la cual nunca le dan importancia ni le escuchan?"2 


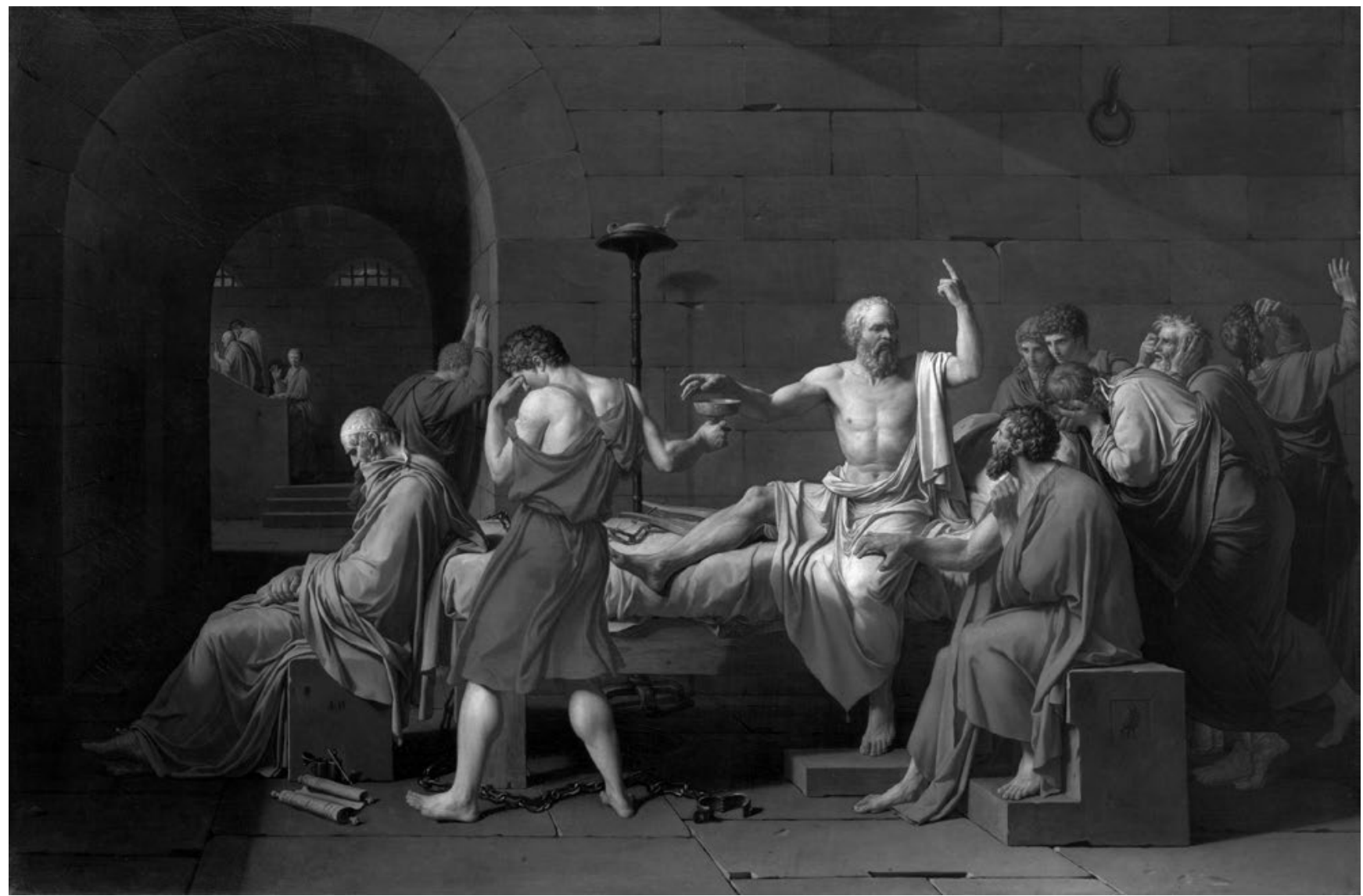

Sócrates entendió que la sabiduría era más poderosa y digna que las ganancia o pérdidas, alabanzas o persecuciones.

Sócrates reconocía cuán maldecida era su sociedad al enfocarse en lo exterior. Se dio a la tarea de iluminar a cuantos más pudiera sobre los errores de su sistema de valores señalando que les faltaba reconocer el valor de construir carácter y el crecimiento del alma. Hoy podríamos entender el alma como la vida espiritual interna, si queremos evitar su connotación deísta. Sócrates sentía el deber de tratar de despertar a sus compañeros ciudadanos de esa niebla convenenciera de la que él creía que padecía la mayoría en Atenas. Al igual que en nuestro capitalismo actual, estos hombres y mujeres atenienses le daban un valor injustificado a la ganancia material, al poder y a la falsa veneración de otros. Se trata de temas sociales que todavía entorpecen a nuestras comunidades regionales, nacionales y globales debido a la avaricia insaciable del capitalismo desenfrenado.

La perspectiva socrática, entonces, sigue teniendo validez, puesto que la mayoría de los ámbitos de poder en los Estados occidentales han depreciado la "autoevaluación", la construcción del carácter y el crecimiento de la vida espiritual a cambio de valorar componentes materiales y externos. Más allá de las necesidades esenciales, los bienes y servicios pueden tener un umbral aparentemente ilimitado cuando se trata de indu- cir un sentimiento de satisfacción. El capitalismo ha causado una percepción sesgada de lo que realmente es el buen vivir. Como lo ha argumentado Gary Gutting en su artículo "Less, Please" ("Menos, por favor") acerca de cómo hemos retorcido el sistema de valores que alaban el consumo en vez del desarrollo del carácter personal: "Se nos exige meternos en un trabajo que haga poca contribución a nuestro buen vivir, más allá de satisfacer nuestras necesidades materiales, y nos insta a creer, falsamente, que de lo que se trata la buena vida es de acumular posesiones materiales". 3

Es comprensible que estarían en desacuerdo con Sócrates la gente o comunidades particulares que disfrutan un estilo de vida espléndido debido a que no asocian la virtud y la ética socráticas con su deseo insaciable de acumular riqueza. Dirían ellos que disfrutan de la mejor versión que existe de la buena vida y que nunca tuvieron necesidad de reconocer ningún empeño metafísico ni considerar las necesidades de los demás ciudadanos. Esto puede aparecer como verdadero para algunos, aunque cualquiera podía acceder a la perspectiva socrática sobre el buen vivir. Sólo había que estar dispuesto a sofocar las tentaciones de la ganancia material y el alabo social. La crítica socrática 
se aplicaba a todos y no sólo a quienes fuesen sordos moralmente para obtener ganancias y alabo a costa de los demás.

Según Sócrates, la satisfacción que se obtenía a partir de la búsqueda del buen vivir era mucho más remunerativa que el alivio fugaz que se pudiera obtener de la posesión de cosas o momentos. Debido al desarrollo capitalista y el enorme consumo de bienes materiales, nuestra sociedad se ha desensibilizado por la apabullante publicidad y mercadotecnia que estimulan todas nuestras interacciones. Esto ha causado que la mayoría de la población consuma sin cuestionarse, eliminando así su autonomía y su habilidad para pensar críticamente.

Este tipo de estado mental parece ser el que frustraba a Sócrates acerca de sus compañeros atenienses: que estaban dispuestos a entregar su capacidad de raciocinio y virtud a cambio de la fastuosidad, las posesiones y el prestigio. El propio Sócrates reconocía que su bulliciosa conciencia sobre el consumismo molestaba a los "sabios y poderosos" de Atenas. Pero creía que sus conciudadanos podrían lograr el buen vivir siempre y cuando pudiesen valorar y apreciar el pensamiento crítico, la autoevaluación y la consideración del prójimo. Estos preceptos siguen siendo importantes para la sociedad del siglo XXI.

Los humanos por lo general creemos que sabemos lo que queremos y, aunque estamos llenos de potencial y ambición, también tenemos limitaciones y defectos nocivos. Estos últimos son los que han explotado las clases dominantes del capitalismo para difundir su propio sistema de valores. El esfuerzo que se necesita para sumarse a las virtudes que Sócrates valoraba supone no esperar su visualización palpable ni el reconocimiento instantáneo por los demás. Dichas virtudes, por tanto, entran en conflicto con el acondicionamiento consumista al que nos han acostumbrado en el capitalismo contemporáneo, que se podría asociar con lo que Karl Marx llamó "fetichismo de la mercancía" en El Capital. ${ }^{4}$ Esta famosa frase de Marx significa que con el intercambio de mercancías perdemos la perspectiva para entender las relaciones sociales que supone que cuando compramos algo entramos en relación con otras personas, con sus productores. El fetichismo de la mercancía hace aparecer a los objetos producidos e intercambiados por los humanos como si dichos objetos entraran en relación entre sí mismos, como una relación entre cosas. Se efectúa así la externalización del consumismo gobernado por la mercadotecnia, la publicidad y los reconocimientos de los demás.

Tenemos pues, dos métodos de veneración o realización humana en conflicto: el interno y el externo. El conflicto entre estos dos métodos de veneración ha transcurrido por mucho tiempo - por lo menos desde la época socrática y posiblemente desde que el intercambio de mercancías fue mediado por el dinero - . El esfuerzo de Sócrates por iluminar o despertar a los jóvenes atenienses equivale a la sugerencia que nos hace Gutting de desarrollar nuestra habilidad crítica para tomar decisiones dentro de estas posibilidades internas y externas. La habilidad de los humanos para adaptarse al cambio demuestra su perseverancia. A través de la educación, posiblemente podamos recuperar el valor de la perspectiva socrática de que el asunto del hombre y de la mujer - de los humanos es pensar, es decir, plantearnos preguntas.

\section{$-\operatorname{notas} \cdot-$}

\footnotetext{
' Platón (i963), The Trial and Death of Socrates, Benjamin Jowett (trans.), Nueva York, The Heritage Press, p. 83.

'Idem.
}

\footnotetext{
${ }^{3}$ Gary Gutting (2012), "Less, Please: Capitalism \& The Good Life", Commonseal Magazine, 26 de diciembre, p. I, disponible en www.commonwealmagazine.org/print/6574

${ }^{4}$ Karl Marx, El capital.
} 